\title{
Renal follow up of premature infants with and without perinatal indomethacin exposure
}

\author{
R Ojala, M Ala-Houhala, S Ahonen, A Harmoinen, V Turjanmaa, S Ikonen, O Tammela
}

\begin{abstract}
Aims-To evaluate early childhood renal growth, structure, and function in children born at less than 33 weeks gestation and to investigate possible independent effects of perinatal indomethacin exposure.

Methods-A total of 66 children born at less than 33 weeks gestation, 31 of them with perinatal indomethacin exposure (study group) and 35 without (control group), were examined at 2-4 years of age. Serum cystatin $\mathrm{C}$ and protein; plasma creatinine, sodium, and potassium; urine protein, calcium:creatinine ratios, and $\alpha_{1}$ microglobulin; and glomerular filtration rate (GFR) were determined. Renal sonography examinations were performed.
\end{abstract}

Results-The mean serum cystatin $\mathrm{C}$ concentrations were slightly higher in the control group than in the study group. Mean values of serum protein, and plasma creatinine and sodium did not differ between the groups, neither did median plasma potassium concentrations and urine protein:creatinine and calcium:creatinine ratios. None had tubular proteinuria. Abnormal GFR $\left(<89 \mathrm{ml} / \mathrm{min} / 1.73 \mathrm{~m}^{2}\right)$ was found in one case in each group and renal structural abnormalities in five in each group. In logistic regression analysis the duration of umbilical artery catheter (UAC) use and furosemide treatment emerged as the significant independent risk factors for renal structural abnormalities. Furosemide treatment and assisted ventilation remained the risk factors associated with renal abnormalities in general-that is, functional and/or structural abnormal findings.

Conclusion-Perinatal indomethacin does not seem to affect long term renal growth, structure, or function in children born at less than 33 weeks gestation. Duration of UAC use, furosemide treatment, and assisted ventilation may be correlated with later renal structural and functional abnormalities.

(Arch Dis Child Fetal Neonatal Ed 2001;84:F28-F33)

Keywords: preterm infants; indomethacin; renal; follow up

epartment of Clinica

Physiology, Tampere

University Hospital

V Turjanmaa

Correspondence to:

Dr Ojala

riitta.1.ojala@uta.fi

Accepted 10 August 2000 antenatally as a tocolytic agent and in the treatment of polyhydramnion, and postnatally for pharmacological closure of patent ductus arteriosus (PDA). In preterm infants, short term prenatal exposure to indomethacin has been shown to impair kidney function and reduce glomerular filtration rate (GFR) values three days after birth, ${ }^{12}$ whereas exposure to indomethacin after birth has been reported to alter the postnatal increase in $\mathrm{GFR}^{3}$ and cause a transient decrease in urine output, increased creatinine values, and urea retention. ${ }^{4}$ In general, subsequent renal structure and function have previously been assessed in small groups of preterm infants ${ }^{6}$; the possible long term effects of perinatal indomethacin exposure on renal status in these infants have not been studied.

The objectives in the present investigation were: (1) to evaluate renal function, growth, and structure in early childhood in children born at less than 33 weeks gestation, with and without perinatal exposure to indomethacin; and (2) to investigate the possible independent role of indomethacin in abnormal renal findings in these children.

\section{Patients and methods}

PATIENTS

The study was approved by the Ethical Committee of Tampere University Hospital and carried out with signed parental consent. The study original population comprised 301 children born in the hospital at less than 33 weeks gestation between 1993 and 1996. Of these, 45 had died and 85 were excluded because: (1) data on maternal indomethacin use were missing (15 children); (2) the mother had received doses of indomethacin less than $150 \mathrm{mg} /$ day during the last trimester in cases where indomethacin had not been administered postnatally (69 children); or (3) ibuprofen had been used postnatally for closure of PDA (one case). Eleven patients could not be contacted because of a missing address. The remaining 160 children, 74 with and 86 without exposure to indomethacin, were invited to attend for examinations which took place between September 1997 and June 1999. The parents of 96 children refused participation. The main reasons for refusal included living a long distance from the hospital (40 children), the child's fearfulness, and complexity of the study protocol. A more simple assessment was then suggested, and in six cases the parents allowed their children to go through the examinations without multiple blood sampling. Altogether the parents of 66 (41\%) consented to allow their children to participate in 
the study. The study group consisted of 31 patients, of whom six had been exposed to indomethacin only antenatally, 12 only postnatally, and 13 both ante- and postnatally. Antenatal exposure was defined as maternal indomethacin treatment during the last trimester of pregnancy for tocolysis or to reduce polyhydramnion at a dosage of at least 150 $\mathrm{mg} /$ day. $^{7}$ The remaining 35 patients were controls not exposed to indomethacin during the perinatal period.

PERINATAL HISTORY

In the neonatal unit, indomethacin was used for pharmacological closure of a haemodynamically significant PDA if no contraindications, including oliguria $(<0.5 \mathrm{ml} / \mathrm{kg} / \mathrm{h})$ or raised creatinine values $(>150 \mu \mathrm{mol} / \mathrm{l})$, were present. Routine management of umbilical artery catheters (UAC) included positioning of the tip above the diaphragmatic level as well as continuous infusion of a heparinised solution. The catheters were used as an infusion route for all parenteral nutrition solutions, including calcium, intravenous medications, and blood products except packed red cells.

Enteral feeding with pooled breast milk was started if possible on the first day of life, and enteral vitamin $\mathrm{D}$ supplementation at 10 $\mu \mathrm{g} /$ day at the age of one week. Infants with birth weights less than $1500 \mathrm{~g}$ received breast milk, fortified with protein and phosphate (PreSemp, $5 \mathrm{~g} / 100 \mathrm{ml}$, the dietary calcium: phosphate ratio being $1.5: 1$ ) as soon as they were on full enteral feeds and until they attained a weight of 2000 g. Enteral calcium supplementation was used only in hypocalcaemic children. Parenteral nutrition commenced on the second day of life if enteral feeding was contraindicated or not tolerated, and it was continued as partial nutritional support until the infant was on full enteral feeds.

No routine renal sonography examinations were made during the primary hospitalisation. One female patient had a hypertensive crisis and acute renal failure, which was considered a complication of a UAC, during the neonatal period. Peritoneal dialysis was maintained for five days, after which renal function recovered slowly; antihypertensive medication was required until nephrectomy of a non-functioning rudimentary left kidney was performed at the age of 1.8 years. Three patients had creatinine concentrations $>150 \mu \mathrm{mol} / 1$ as a consequence of postnatal indomethacin treatment. One patient in the control group suffered recurrent episodes of macroscopic haematuria associated with courses of netilmycin and raised urine $\beta_{2}$ microglobulin concentrations during the neonatal period. In the remaining children, no evidence of renal functional abnormalities or hypertension was seen during primary hospitalisation.

METHODS

All children were interviewed and examined at 2 to 4 years of age by the same physician. General health history, number of previous urinary tract infections, and regular medications were recorded and weights and lengths measured.
Blood pressure (BP) was measured by an oscillometric method (DINAMAP Adult/Paediatric and Neonatal Vital Signs Monitor Model 1846 SX, Criticon, Inc., USA), which has been chosen for current use in the hospital, on the right arm in the sitting position, using a child cuff or a small adult cuff, ensuring that it covered two thirds of the upper arm.

Blood samples (for serum cystatin C and protein, and plasma creatinine, sodium, and potassium) were drawn, together with random spot urine samples for analysis of protein, calcium, creatinine, and $\alpha_{1}$ microglobulin content. Serum cystatin C concentrations were determined by a particle enhanced turbidimetric immunoassay (Dako, Glostrup, Denmark) using a Hitachi 704 analyser. ${ }^{8}$ Plasma creatinine measurements were based on the Jaffe reaction $^{9}$ using the same instrument. Urinary $\alpha_{1}$ microglobulin was measured nephelometrically (Behring BN II nephelometer, Dade Behring, Marburg, Germany) with a sensitivity of about $5 \mathrm{mg} / \mathrm{l}$. GFR was determined by plasma clearance of ${ }^{51} \mathrm{Cr}$-EDTA assessed by the single injection method. ${ }^{10}$ A normal GFR value of $89-165 \mathrm{ml} / \mathrm{min} / 1.73 \mathrm{~m}^{2}$ was assumed. ${ }^{11}$

All patients underwent renal sonography examinations, performed by an experienced paediatric radiologist who was unaware of the perinatal history. All patients underwent renal colour Doppler sonography with a Acuson Sequoia (Mountain View, California, USA) scanner. Both kidneys were scanned in prone, oblique, and supine positions, using 4V2 vector, 8C4 curvilinear, and 8L5 linear transducers. The size, structure, and echogenicity of the kidneys were first evaluated. Measurements of the kidney length were compared with a graph for length. ${ }^{12}$ Renal resistance indexes (RI) were calculated from pulse Doppler waveforms obtained from intrarenal arteries and compared with age dependency values. ${ }^{13}$ No sedation was employed during the examination. Definition of RI failed in only three children in the control group in consequence of the patient's restlessness.

\section{STATISTICAL ANALYSIS}

The data were analysed using the Statistical Package for Social Sciences (SPSS) for Windows and Graphpad Instat. Continuous data were analysed using an independent samples $t$ test or the Mann-Whitney U test; categorised data were analysed using using Fisher's exact test or the $\chi^{2}$ test as appropriate. To identify potential factors (birth weight, gestational age, sex, Apgar score $<7$ at 5 minutes of age, small for gestational age, duration of mechanical ventilation, oxygen supplementation and UAC use, exposure to indomethacin, inotropics, furosemide, netilmycin, and cephalosporins, and calcium supplementation) which might have contributed to abnormal renal sonographic, GFR, and BP findings, logistic regression analysis with a backward stepwise method was used. A p value less than 0.05 was considered significant. 
Table 1 Perinatal clinical characteristics

\begin{tabular}{llll}
\hline Characteristic & Study group $(n=31)$ & Control group $(n=35)$ & p value \\
\hline Male gender & 42 & 54 & 0.450 \\
Gestational age (wk) & $28(24-32)$ & $31(24-32)$ & 0.003 \\
Birth weight (g) & $1150(670-2060)$ & $1360(680-2680)$ & 0.118 \\
Small for gestational age & 10 & 29 & 0.068 \\
Singleton births & 58 & 80 & 0.065 \\
Apgar score $<7$ at 5 min & 42 & 20 & 0.065 \\
Umbilical artery catheter & 61 & 43 & 0.212 \\
$\quad$ Duration of use (days) & $4(0-18)$ & $0(0-13)$ & 0.032 \\
RDS & 61 & 17 & $<0.001$ \\
Assisted ventilation & 90 & 46 & $<0.001$ \\
Duration of use (days) & $10(0-59)$ & $0(0-65)$ & 0.001 \\
Oxygen supplementation & 100 & $44(0-118)$ & 0.003 \\
$\quad$ Duration of use (days) & $42(4-115)$ & 43 & 0.001 \\
Treatment with inotropics & 55 & $0(0-4.6)$ & 0.240 \\
$\quad$ Duration of use (days) & $0.5(0-6.6)$ & $41(19-123)$ & 0.004 \\
Primary hospitalisation & $78(27-143)$ & & \\
$\quad$ Duration of use (days) & 796 & \\
\hline
\end{tabular}

Categoric data are shown as $\%$ and continuous data as median (range).

Table 2 Exposure to nephrotoxic drugs during primary hospitalisation

\begin{tabular}{|c|c|c|c|}
\hline Characteristic & $\begin{array}{l}\text { Study group } \\
(n=31)\end{array}$ & $\begin{array}{l}\text { Control group } \\
(n=35)\end{array}$ & $p$ value \\
\hline $\begin{array}{l}\text { Cumulative dosage of: } \\
\text { antenatal indomethacin }(\mathrm{mg}) \\
\text { postnatal indomethacin }(\mathrm{mg} / \mathrm{kg})\end{array}$ & $\begin{array}{l}500(100-1645) \\
0.65(0.37-1.20)\end{array}$ & & \\
\hline Treatment with netilmycin & 100 & 66 & $<0.001$ \\
\hline Duration of use (days) & $10(2-34)$ & $5(0-20)$ & 0.003 \\
\hline Treatment with cephalosporins & 61 & 43 & 0.212 \\
\hline Duration of use (days) & $6(0-30)$ & $0(0-19)$ & 0.086 \\
\hline Treatment with vancomycin & 19 & 14 & 0.743 \\
\hline Duration of use (days) & $0(0-18)$ & $0(0-16)$ & 0.656 \\
\hline Treatment with furosemide & 100 & 46 & $<0.001$ \\
\hline Duration of use (days) & $6(1-48)$ & $0(0-15)$ & $<0.001$ \\
\hline $\begin{array}{l}\text { Treatment with spironolactone and } \\
\text { hydrochlorothiazide }\end{array}$ & 39 & 20 & 0.110 \\
\hline Duration of use (days) & $0(0-98)$ & $0(0-51)$ & 0.110 \\
\hline
\end{tabular}

Categorised data are shown as \% and continuous data as median (range).

\section{Results}

NEONATAL CHARACTERISTICS

The children with perinatal indomethacin exposure were more premature, and had a longer duration of UAC use, assisted ventilation, oxygen supplementation, and primary hospitalisation compared to the controls. Duration of treatment with inotropics was similar (table 1). Eleven children in the study group and six in the control group had received dexamethasone $(\mathrm{p}=0.101)$. The median duration of this treatment (0 (range $0-21)$ versus $0(0-19)$ days, $\mathrm{p}=0.070$ ) was similar in the two groups. Twenty one patients in each group had received fortified breast milk. There were no differences in median age at the start (17 $(5-54)$ versus $14(7-45)$ days, $\mathrm{p}=0.226)$ or in the duration of fortification $(27(0-98)$ versus 26 (0-99) days, $\mathrm{p}=0.481)$. Seven children in the study group and three in the control group had intraventricular haemorrhage $(p=0.171)$, and three in each group had cystic periventricular leucomalacia $(\mathrm{p}=1.000)$. The number of cases of necrotising enterocolitis ${ }^{14}$ in the respective groups were seven versus four $(\mathrm{p}=0.324)$ and of cases with bronchopulmonary dysplasia ${ }^{15}$ were six versus five $(\mathrm{p}=0.743)$.

Cumulative antenatal exposure to indomethacin in the study group ranged between 100 and $1645 \mathrm{mg}$; the cumulative postnatal dosage received was between 0.37 and $1.20 \mathrm{mg} / \mathrm{kg}$, the duration of postnatal indomethacin treatment ranging from one to eight days. PDA was surgically ligated in five children in the study group and in none in the control group. The duration of treatment with cephalosporins and vancomycin was similar in the two groups (table 2). No patient had received amphotericin B. The study group had received netilmycin and furosemide for longer than the controls; all patients in the study group and only $16(46 \%)$ in the control group had received furosemide $(\mathrm{p}<0.001)$. There was no significant difference between the groups in duration of treatment with the combination of spironolactone and hydrochlorothiazide (table 2)

Analysis of the perinatal characteristics of the 94 eligible children (43 with and 51 without perinatal exposure to indomethacin), who did not attend for the examinations because of parental refusal, revealed that gestational age, birth weight, gender, incidence of singleton births, five minute Apgar score $<7$, respiratory distress syndrome, duration of UAC use and mechanical ventilation, exposure to perinatal indomethacin, postnatal antibiotic treatment, and duration of primary hospitalisation were similar to the corresponding characteristics among the cases examined (data not shown).

CHARACTERISTICS OF CHILDREN AT EXAMINATION The children in the study group were slightly older than those in the control group at the time of examination (mean (SD) 3.7 (0.6) versus $3.3(0.8)$ years, $p=0.031)$. One child in the study group and two in the control group had had one lower urinary tract infection, and one in the study group an episode of pyelonephritis. In addition to the child with previous unilateral nephrectomy, one child in the study group had a previously diagnosed bilateral vesicouretral reflux, grade 2 . Seven children were asthmatic and received regular inhaled glucocorticoid treatment, and three were on vigabatrin and/or sodium valproate medication for epilepsy. Four children in the study group and two in the control group had cerebral palsy, and one in the control group had psychomotor retardation of unknown cause.

Mean heights $(-0.3(1.3)$ versus -0.2 (1.0) $\mathrm{SD}, \mathrm{p}=0.910)$ and weights for heights $(-2$ (11) versus $-5(9) \%, p=0.296)$ in the study and control groups were similar as plotted on Finnish standardised growth charts. ${ }^{16}$ Also mean systolic (107 (12) versus 105 (14) mm $\mathrm{Hg}, \mathrm{p}=0.400)$ and diastolic (65 (11) versus 62 (9) $\mathrm{mm} \mathrm{Hg}, \mathrm{p}=0.223$ ) BP were no different. Three children in the study group and two controls had both systolic and diastolic BP higher than the 95th percentile; one child in the study group had diastolic BP higher than the 95th percentile. Of these, two in the study group and one in the control group had systolic and diastolic BP values above the 99th percentile for age. ${ }^{17}$

RENAL FUNCTION TESTS

There were no significant differences between the groups for plasma creatinine, sodium, and potassium, and serum protein concentrations (table 3). Mean serum cystatin C concentrations were slightly higher in the control group, 
Table 3 Renal function tests

\begin{tabular}{|c|c|c|c|}
\hline Characteristic & Study group $(n=31)$ & Control group $(n=35)$ & $p$ value \\
\hline Plasma creatinine $(\mu \mathrm{mol} / \mathrm{l})^{\star}$ & $38.8(5.3)$ & $36.6(6.0)$ & 0.137 \\
\hline Plasma sodium $(\mathrm{mmol} / \mathrm{l})^{\star}$ & $141.9(1.9)$ & $141.3(1.9)$ & 0.256 \\
\hline Plasma potassium $(\mathrm{mmol} / \mathrm{l}) \dagger$ & $4.0(3.5-4.7)$ & $4.1(3.7-4.6)$ & 0.095 \\
\hline Serum protein $(\mathrm{g} / \mathrm{l})^{\star}$ & $70.4(4.2)$ & $68.7(4.3)$ & 0.111 \\
\hline Serum cystatin $C(\mathrm{mg} / \mathrm{l})^{\star}$ & $0.92(0.17)$ & $1.02(0.17)$ & 0.026 \\
\hline $\begin{array}{l}\text { Urinary calcium:creatinine ratio } \\
(\mathrm{mmol} / \mathrm{mmol}) \dagger\end{array}$ & $0.36(0.08-1.21)$ & $0.32(0.09-0.82)$ & 0.299 \\
\hline $\begin{array}{l}\text { Urinary protein:creatinine ratio } \\
(\mathrm{mg} / \mu \mathrm{mol}) \dagger\end{array}$ & $0.016(0.006-0.147)$ & $0.017(0.007-0.158)$ & 0.389 \\
\hline $\operatorname{GFR}\left(\mathrm{ml} / \mathrm{min} / 1.73 \mathrm{~m}^{2}\right) \dagger$ & $121(86-164)$ & $115(86-148)$ & 0.177 \\
\hline
\end{tabular}

${ }^{\star}$ Mean (SD); †median (range).

Table 4 Logistic regression analysis for risk factors underlying abnormal renal sonographic findings

\begin{tabular}{lll}
\hline Variable & OR & $95 \%$ CI \\
\hline Variables in the final equation & & \\
Furosemide treatment (days) & 1.179 & 1.031 to 1.347 \\
Umbilical artery catheter use (days) & 1.259 & 1.003 to 1.581 \\
Indomethacin treatment & 0.076 & 0.004 to 1.499 \\
Apgar score <7 at 5 minutes of age & 7.849 & 0.533 to 115.6 \\
Duration of mechanical ventilation (days) & 1.120 & 0.995 to 1.261 \\
Treatment with inotropics (days) & 0.972 & 0.938 to 1.007 \\
Treatment with cephalosporins (days) & 0.773 & 0.572 to 1.044 \\
Variables not in the final equation & & \\
Birth weight & & \\
Gestational age & & \\
Small for gestational age & \\
Gender & \\
Duration of oxygen supplementation & \\
Treatment with netilmycin & \\
Calcium supplementation & \\
\hline
\end{tabular}

OR, odds ratio; CI, confidence interval.

but were lower than $1.4 \mathrm{mg} / \mathrm{l}$ in all cases. Furthermore, the respective median urine calcium:creatinine and protein:calcium ratios were similar. A urine calcium:creatinine ratio over 0.8 was found in one child in each group. Only three patients in the study group and one in the control group had measurable amounts of $\alpha_{1}$ microglobulin $(5.1-5.9 \mathrm{mg} / \mathrm{l})$ in their urine samples. Thus none had significant tubular proteinuria. The median (range) estimated GFR was $121(86-164) \mathrm{ml} / \mathrm{min} / 1.73 \mathrm{~m}^{2}$ in the study group and $115(86-148)$ in the control group. One child in each group had a GFR below the normal range $\left(86 \mathrm{ml} / \mathrm{min} / 1.73 \mathrm{~m}^{2}\right.$ in both cases). ${ }^{11}$

No kidney sizes below normal for height were found at ultrasonographic examination. Ten children, five in each group, yielded abnormal renal structural findings. In the study group, one child had bilateral nephrocalcinosis, two had size disproportion (size difference between the kidneys more than one SD), one had enlarged kidneys (2 SD) combined with bilateral decreased corticomedullary differentiation and unilateral prehydronephrosis, and one had unilateral nephrectomy and nephrocalcinosis of the remaining kidney. In the control group, two children had unilateral hydronephrosis, one had unilateral nephrocalcinosis, one had size disproportion, and one had bilateral decreased corticomedullary differentiation. Two children with renal nephrocalcinosis, both with an abnormal renal echodensity, and two with size disproportion of the kidneys had received furosemide treatment and had an UAC during their primary hospitalisation. The hydronephrotic patients had not been thus exposed.
In the Doppler examinations eight patients, five in the study group and three in the control group had RI values over the norm for age in one or both kidneys. ${ }^{13}$ One of them had an increased BP and decreased renal corticomedullary differentiation; the others had no other renal abnormalities.

RISK FACTORS UNDERLYING ABNORMAL RENAL FINDINGS

In the logistic regression analysis, duration of furosemide treatment and duration of UAC use had a significant independent association with renal structural sonographic abnormalities; indomethacin exposure showed no such correlation (table 4 ).

In the analysis of potential sources of risk associated with abnormal renal findings in general (including at least one of the following: structural sonographic findings, decreased GFR, and both systolic and diastolic BP higher than the 95th percentile for age), duration of furosemide treatment (odds ratio 1.156, 95\% confidence interval 1.024 to 1.305$)$ and duration of mechanical ventilation (odds ratio 1.157 , CI 1.040 to 1.287 ) emerged as the only significant factors.

\section{Discussion}

Analysis of the data presented suggests that perinatal indomethacin treatment had no long term influence on renal structure and function in the present population as evaluated in early childhood. In general, abnormalities in renal function tests were uncommon, but renal structural findings in sonography were frequent, being equally divided beween the groups with or without exposure to indomethacin. The children with previous perinatal exposure to indomethacin were younger at the time of examination than the controls and they had also been significantly more premature and smaller and sicker during their neonatal period. Many potential confounding factors affecting comparison between the groups were therefore present. Indications for antenatal and postnatal indomethacin use might be related to the fact that probability of perinatal indomethacin exposure seems to increase with decreasing gestational age, as shown in our previous work. ${ }^{7}$ It was not possible therefore to find well matched controls, according to their neonatal characteristics. An adverse effect of indomethacin balanced by the group differences seems, however, unlikely because of the more severe perinatal history of the study group. Instead, duration of UAC use and furosemide treatment were found to be significant independent risk factors correlated with renal structural abnormalities.

Aortic thrombosis has been reported to be associated with UAC use in approximately one quarter of cases, ${ }^{18}{ }^{19}$ and to be a cause of abnormalities in renal haemodynamics even in the absence of clinical symptoms. ${ }^{19}$ Of ten 3-3.5 year old study subjects, who had had UAC associated aortic thrombi, three had renovascular hypertension, and seven had renal size below normal, including two with size discrepancy between the kidneys; seven age 
matched control subjects showed normal sonography. ${ }^{20}$ In our patients, renal sonography examinations had not been undertaken systematically during the neonatal period and, with one exception, none of the cases studied showed any evidence of a previous symptomatic aortic thrombosis. Low birth weight, catheter placement above the level of the renal arteries, and use of the catheter as a calcium administration route have been described as risk factors associated with aortic thrombus formation ${ }^{18}$; therefore, some of the management practises for UAC used in our patients might have tended to increase such a risk. Thus, the possibility of such a complication during the neonatal period cannot be ruled out in our patients with abnormal renal structural findings.

In very low birth weight infants the incidence of nephrocalcinosis varies from $8 \%$ to $64 \%{ }^{21} 22$ following furosemide therapy, ${ }^{22-24}$ but also without furosemide treatment. ${ }^{22}{ }^{25}{ }^{26}$ Other factors associated with renal calcification include immaturity, ${ }^{22}{ }^{25}$ oxygen therapy, ${ }^{26}$ administration of glucocorticoids and theophylline, ${ }^{27}$ exogenous calcium supplementation, ${ }^{22}$ chronic dehydration, prolonged duration of parenteral nutrition, low phosphorus intake, high intake of vitamin $\mathrm{D}$, immobilisation, and other factors causing hypercalciuria. ${ }^{28}{ }^{29}$ The renal changes are in most cases transient, but in some children renal calcifications may last several years. ${ }^{627} 3031$ The patients studied here had been exposed to many of the mentioned risk factors, and it is possible that in some cases renal calcifications may have been present but already resolved before the examinations. The present results also suggest that increased duration of furosemide treatment during the neonatal period is a major risk factor for long persisting renal structural abnormalities in preterm infants.

Abnormal creatinine values and glomerular filtration rates have been found to be frequent in small groups of preterm infants with renal calcifications studied at the age of 1-4.5 years. ${ }^{6}{ }^{30}$ However, in 11 preterm children who had had renal calcification as neonates and 17 controls without previous calcifications examined at the age of $4-5$ years, evidence of renal dysfunction independent of the history of renal calcification has been found. Eight children had abnormal calcium load test results and in all cases studied the renal concentrating ability evaluated by means of a desmopressin test was below published normal values. Glomerular filtration rates, assessed only in patients with nephrocalcinosis, were below normal in all cases. ${ }^{31}$ In our significantly larger group of children born preterm, renal function was found to be good; serum cystatin C, plasma creatinine, and electrolyte values were within the normal range in all cases, both patients with abnormal GFR having values only slightly below normal. Although renal concentration ability was not evaluated here, in the light of previous studies our tests show that long term prognosis of renal function was better than expected in the present study population.

\section{Key messages}

- Renal structural abnormalities occur commonly in children who were born prematurely at less than 33 weeks gestation

- There is an association between the duration of umbilical artery catheter use and furosemide treatment in the neonatal period with later renal structural abnormalities

- Premature infants who require umbilical artery catheterisation and furosemide therapy constitute a high risk group in whom follow up of renal function is indicated

Hypoxia, hypotension, and nephrotoxic drugs, especially aminoglycosides, may cause renal cortical or medullary damage during the neonatal period, possibly leading to prolonged renal dysfunction. ${ }^{31}$ Our analysis of abnormal renal findings in general, including structural abnormalities, abnormal GFR, and increased $\mathrm{BP}$, showed that in addition to UAC use and furosemide treatment, duration of assisted ventilation seemed to be an independent significant risk factor. It is possible that those with a prolonged need for ventilatory support had also had prolonged exposure to hypoxia and thus ran an increased risk of renal damage. Duration of assisted ventilation is also related to duration of immobilisation and carries a risk of chronic lung disease, both factors having adverse effects on renal function in increasing the risk of nephrocalcinosis. The absence here of correlation between abnormal renal findings and the inotropic treatment received by about half of our patients for hypotension suggests that the use of inotropics might have alleviated or prevented the adverse effects of hypotension on renal function. In spite of the fact that exposure to aminoglycosides during primary hospitalisation was frequent in the present study population, the duration of this exposure would seem to have had no long term effects on renal function. Use of other nephrotoxic drugs was low in our patients and it is therefore difficult to draw conclusions as to their independent effects on the results.

Compared with previous renal follow up studies, ${ }^{6}$ one of the largest groups of preterm infants was examined in the present study. Although less than half of the eligible cases eventually participated, analysis of the nonparticipating patients showed similar neonatal characteristics to those studied. It may thus be suggested that the risk of a selection bias is small and our results may be fairly representative of the total study population. Our patients were subjected to a cross sectional evaluation in quite a narrow age range; therefore, as both many renal structural and functional abnormalities and the incidence of renovascular hypertension have a tendencey to resolve even during the first months after discharge from hospital, ${ }^{32}$ the true incidence of these complications before the examinations in the present 
population remain unknown. On the other hand, the true number of patients with hypertension cannot be given until the diagnosis has been confirmed with repeated BP measurements or preferably with ambulatory BP measurements. It cannot, moreover, be ruled out that with increasing age some renal problems in the patients might still manifest themselves. At least in the patients with renal abnormalities, further follow up is called for, as worsening of renal impairment is possible with growth.

In conclusion, perinatal indomethacin treatment does not seem to affect long term renal growth, structure, or function, but renal structural abnormalities occurred frequently in children born at less than 33 weeks gestation, examined at the age of 2-4 years. Duration of UAC use, furosemide treatment, and assisted ventilation during the neonatal period may be correlated with later renal structural and functional abnormalities. Follow up of renal function and growth would appear to be indicated in the risk groups presented.

The study was supported by the Foundation of Paediatric Research, Finland and the Medical Research Fund of Tampere University Hospital.

1 van der Heijden AJ, Provoost AP, Nauta J, et al. Renal functional impairment in preterm neonates related to intrauteine indomethacin exposure. Pediatr Res 1988;24:644-8.

2 van den Anker JN, Hop WCJ, de Groot R, et al. Effects of prenatal exposure to betamethasone and indomethacin on the glomerular filtration rate in the preterm infant. Pediatr Res 1994;36:578-81.

3 van den Anker JN, Hop WCJ, Schoemaker RC, van der Heijden BJ, Neijens HJ, de Groot R. Ceftazidime pharmacokinetics in preterm infants: effect of postnatal age and cokinetics in preterm infants: effect of postnatal age and postnatal exposure

4 Seyberth HW, Rascher W, Hackenthal R, Wille L. Effect of prolonged indomethacin therapy on renal function and selected vasoactive hormones in very-low-birth-weight infants with symptomatic patent ductus arteriosus. F Pediatr 1983;103:979-84

5 Tammela $\mathrm{O}$, Ojala $\mathrm{R}$, Iivainen $\mathrm{T}$, et al. Short versus prolonged indomethacin therapy for patent ductus arteriosus in preterm infants. F Pediatr 1999;134:552-7.

6 Downing GJ, Egelhoff JC, Daily DK, Thomas MK, Alon U. Kidney function in very low birth weight infants with furosemide-related renal calcifications at ages 1 to 2 years. f Pediatr 1992;120:599-604.

7 Ojala R, Ikonen S, Tammela O. Perinatal indomethacin treatment and neonatal complications in preterm infants. treatment and neonatal comp

8 Ylinen EA, Ala-Houhala M, Harmoinen APT, Knip M. Cystatin $\mathrm{C}$ as a marker for glomerular filtration rate in Cystatin C as a marker for glomerular filtration
pediatric patients. Pediatr Nephrol 1999;13:506-9.

9 Bartels H, Böhmer M, Heierli C. SerumKreatininbestimmung ohne Enteiweissen. Clin Chim Acta 1972;37:193-7.
10 Garnett ES, Parsons V, Veall N. Measurement of glomerular filtration rate in man using a $51 \mathrm{Cr}$-edetic-acid complex. Lancet 1967;15:818-19.

11 Goldsmith DI, Novello AC. Clinical and laboratory evaluation of renal function. In: Edelman CM, ed. Paediatric kidney disease, 2nd edn. London: Little, Brown, 1992:467.

12 Dinkel E, Ertel M, Dittrich M, Peters H, Berres M, SchulteWissermann H. Kidney size in childhood. Sonographical growth charts for kidney length and volume. Pediatr Radiol 1985;15:38-43.

13 Lin GJ, Cher TW. Renal vascular resistance in normal children-a color Doppler study. Pediatr Nephrol 1997;11:182-5.

14 Walsh M, Kliegmann R. Necrotizing enterocolitis: treatment based on staging criteria. Pediatr Clin North Am 1986;33:179-201.

15 Shennan AT, Dunn MS, Ohlsson A, Lennox K, Hoskins EM. Abnormal pulmonary outcomes in premature infants: prediction from oxygen requirement in neonatal period. Pediatrics 1988;82:527-32.

16 Standard growth chart. Foundation of Paediatric Research in Finland, 1994.

17 National Heart, Lung, and Blood Institute. Report of the Second Task Force on Blood Pressure Control in Children-1987. Pediatrics 1987;79:1-25.

18 Seibert JJ, Taylor BJ, Williamson SL, Williams BJ, Szabo JS, Corbitt SL. Sonographic detection of neonatal umbilicalartery thrombosis: clinical correlation. $A f R$ 1987;148:965-8.

19 Glickstein JS, Rutkowski M, Schacht R, Friedman D. Renal blood flow velocity in neonates with and without umbilical artery catheters. $\mathcal{F}$ Clin Ultrasound 1994;22:543-50.

20 Seibert JJ, Northington FJ, Miers JF, Taylor BJ. Aortic thrombosis after umbilical artery catheterization in neonates: prevalence of complications on long-term follow-up. AfR 1991;156:567-9.

21 Woolfield N, Haslam R, le Quesne G, Chambers HM, Hogg $\mathrm{R}$, Jureidini $\mathrm{K}$. Ultrasound diagnosis of nephrocalcinosis in preterm infants. Arch Dis Child 1988;63:86-8.

22 Jacinto JS, Modanlou HD, Crade M, Strauss AA, Bosu SK. Renal calcification incidence in very low birth weight infants. Pediatrics 1988;81:31-5.

23 Hufnagle KG, Khan SN, Penn D, Cacciarelli A, Williams P. Renal calcifications: a complication of long-term furosemide therapy in preterm infants. Pediatrics 1982;70:360-3.

24 Alon US, Scagliotti D, Garola RE. Nephrocalcinosis and nephrolithiasis in infants with congestive heart failure treated with furosemide. F Pediatr 1994;125:149-51.

25 Sheu JN, Chen CH, Lue KH, Chen JY, Tsau YK, Chen JH. Renal calcification in very low birth weight infants. $A m \mathcal{F}$ Nephrol 1993;13:6-11.

26 Short A, Cooke RWI. The incidence of renal calcification in preterm infants. Arch Dis Child 1991;66:412-17.

27 Saarela T, Vaarala A, Lanning P, Koivisto M. Incidence, ultrasonic patterns and resolution of nephrocalcinosis in very low birthweight infants. Acta Paediatr 1999;88:65560.

28 Polinsky MS, Kaiser BA, Baluarte HJ. Urolithiasis in childhood. Pediatr Clin North Am 1987;34:683-710.

29 Karlowich MG, Adelman RD. Renal calcification in the first year of life. Pediatr Clin North Am 1995;42:1397-413.

30 Ezzedeen F, Adelman RD, Ahlfors CE. Renal calcification in preterm infants: pathophysiology and long-term sequelae. F Pediatr 1988;113:532-9.

31 Jones CA, King S, Shaw NJ, Judd BA. Renal calcification in preterm infants: follow-up at $4-5$ years. Arch Dis Child 1997;76:F185-9.

32 Payne RM, Martin TC, Bower RJ, Canter CE. Management and follow-up of arterial thrombosis in the neonatal period. F Pediatr 1989;114:853-8. 